Success Breeds Success, Especially When Self-efficacy is Related With a Causality Internal Attribution

El éxito lleva al éxito, especialmente cuando la autoeficacia se relaciona con una atribución interna de causalidad 


\begin{abstract}
Taking the Social Cognitive Theory by Albert Bandura as its starting point, this paper tests the hypothesis that academic self-efficacy influences future academic success through the differential impact of internal and external attribution of past success. Structural Equation Modelling performed with data from a longitudinal sample of 527 university students provides strong evidence supporting the research model. These findings show that past academic success has a positive influence on academic self-efficacy $(p<.001)$ and on future academic success $(p<.001)$. Two processes can then occur: (1) when self-efficacy is related with an internal attribution $(p<.001)$ it has a positive impact on future academic success over time $(p<.001)$; (2) when self-efficacy is related with an external attribution $(p<.001)$ it has a negative impact on future academic success $(p<.05)$. Theoretical and practical implications, as well as its limitations and future research, are discussed.
\end{abstract}

Key words: efficacy beliefs, causal attribution, and success.

\title{
Resumen
}

Considerando la Teoría Cognitiva Social de Albert Bandura, el presente trabajo pone a prueba la hipótesis de que la autoeficacia académica influye en el éxito académico futuro a través del impacto diferencial de la atribución interna y externa de los éxitos pasados. Modelos de Ecuaciones Estructurales en una muestra longitudinal de 527 estudiantes universitarios apoyan el modelo de investigación. Estos resultados muestran que el éxito académico pasado tiene una influencia positiva sobre la autoeficacia académica $(p<.001)$ y sobre el éxito académico futuro $(p<.001)$. Dos procesos pueden entonces ocurrir: (1) cuando la autoeficacia se relaciona con una atribución interna $(p<.001)$ se muestra un impacto positivo sobre el éxito académico futuro a lo largo del tiempo $(p<.001)$; (2) cuando la autoeficacia se relaciona con una atribución externa $(p<.001)$ el impacto sobre el éxito académico futuro es negativo $(p<.05)$. Se discuten las implicaciones de los resultados, sus limitaciones e investigación futura.

Palabras clave: creencias de eficacia, atribución causal, éxito. 


\section{Success Breeds Success, Especially when Self-efficacy is related with a Causality Internal Attribution}

This study looks at one of the most influential psychosocial constructs in Psychology today: selfefficacy. Past research showed the predictive power of self-efficacy in different domains: education, sports, psychotherapy, and work psychology (Bandura, 2001). It seems that the focus of self-efficacy research should be expanded to include the often-ignored mediating influence of attribution analysis (Lyden, Chaney, Danehower, \& Houston, 2002). Another idea that seems to have been neglected by recent literature is the influence of heuristics on judgments of self-efficacy, and the influence of heuristics on judgments about causal attributions concerning past personal experiences in different domains. This study focused on how past academic success predicts self-efficacy, which predicts future academic success depending on the causal attribution (internal vs. external) of past success.

\section{Self-efficacy: the Power of Belief that You Can...}

Self-efficacy represents the core aspect of Bandura's Social-Cognitive Theory. According to Bandura (1997, p. 3), self-efficacy is the "belief in one's capabilities to organise and execute the course of action required to produce given attainments". Expectations about self-efficacy determine whether instrumental actions will be initiated, how much effort will be made and how long it will be sustained when faced with obstacles and failures (Bandura, 2001, 2008).

Self-efficacy has an influence on how we prepare for action because self-related cognitions are a major ingredient in the motivation process and, different levels of self-efficacy can enhance or impede motivation (Bandura, 1997). People with a high level of self-efficacy choose to perform more challenging tasks; set themselves higher goals and stick to them; reshape actions by thinking about them and anticipate either optimistic or pessimistic scenarios in accordance with their level of selfefficacy in a specific domain. Also, highly self-efficacious people put more effort into the actions and stay at it longer than those with low self-efficacy. When difficulties occur, they overcome them more quickly and remain committed to their goals. Research consistently shows that efficacy beliefs make a 
significant contribution to the individual's level of motivation, well-being and performance (Bandura \& Locke, 2003). For example, Lent, Taveira, Sheu and Singley (2009) have shown that self-efficacy and environmental support were predictive of goal progress and academic adjustment, and the latter was predictive of overall life satisfaction among university students.

Although literature has shown that self-efficacy has important consequences, i.e., improving performance (Beas \& Salanova, 2006; Bresó, Schaufeli, \& Salanova, 2011; Salanova, Lorente, Chambel \& Martínez, 2011; Stajkovic \& Luthans, 1998), achieving career success (Lent et al., 2009) and increasing well-being (Bresó, Salanova \& Schaufeli, 2007; Salanova et al., 2003), few studies have examined its antecedents. According to Bandura $(2001,2008)$ people's beliefs in their efficacy could develop from four major sources of influence, which vary in strength and importance: mastery experiences, vicarious experiences, social persuasion and somatic/emotional states.

In this study, we focus on the first of these sources of efficacy beliefs: mastery experiences. Selfefficacy is reported only when events that have been experienced and the results of actions are appraised cognitively. The mastery experience is posited to be the most influential source of selfefficacy information (Bandura, 1997) and there is empirical evidence to support this claim (Klassen, 2004). But the simplistic view that efficacy beliefs are only reflections of past performance does not stand up to empirical scrutiny. Several different factors affect the cognitive processing of information about performance and knowing what these effects are enables us to understand the conditions under which people get the most out of their mastery experiences. Such factors include the perceptions of their capabilities, the perceived difficulty involved in the task, the amount of effort they make while doing the task, the circumstances under which they perform, the temporal pattern of their successes and failures, and the way these enactive experiences are cognitively organised and reconstructed (Bandura, 1997).

In this cognitive process, the causal attribution of performance is of fundamental importance and the causal relation between self-efficacy and personal attributions may be reciprocal. Bandura (1997) 
suggested that cognitive appraisals of the causes of one's behaviour (whether the behaviour is attributed to internal factors such as ability or to external factors such as luck) might have an influence on whether successful task performance will increase self-efficacy beliefs. Bandura (1997) also proposed that efficacy beliefs provide information that leads to the making of causal attribution and this in turn has an impact on performance, with the subsequent development of self-efficacy expectations over time.

\section{Causal Attribution}

Attribution theory describes how people explain their experiences, what type of information they use in making causal inferences, and what they do with that information to answer causal questions (Weiner, 1985). Accordingly, retrospective judgments of the causes of one's performances have motivational effects. As Bandura (1997, p. 123) states "people who credit their successes to personal capabilities and their failures to insufficient effort will undertake difficult tasks and persist in the face of failure. They do this because they see their outcomes as influence-able by how much effort they expend. In contrast, those who ascribe their failures to deficiencies in ability and their successes to situational factors will display low strivings and give up readily when they encounter difficulties". Consequently, past performance affects the beliefs in one's personal capability and serves as the cause of future actions. Weiner (1986) argues that the individual's causal attributions for achievement outcomes determine subsequent achievement strivings. Thus, they are key motivational beliefs.

Research on this topic has identified three dimensions of causal attributions: locus of causality, stability, and controllability of the cause (Weiner, 1985). The locus of causality may be internal to the individual (ability) or external (task situation). The stability dimension categorises the explanation as stable and relatively fixed (ability), or unstable and tending to fluctuate or vary (effort). Finally, the degree of controllability by the individual may be classified as either controllable (strategy) or uncontrollable (task situation). The attribution process is utilised in an attempt to determine the extent to which success is due to internal or external factors, to stable or unstable factors, and to controllable 
or uncontrollable circumstances. Fiske and Taylor (1991) also showed in educational settings, that the dimensions of locus, stability and controllability help us to understand the perceived cause of behaviour and causal attributions have implications for the future.

In the conceptualisations of the relationship between self-efficacy and causal attributions, research (Bandura, 1997; Katzel \& Thompson, 1990) has focused primarily on the locus of causality dimension. As regards its consequences on self-efficacy, Stajkovic and Sommer (2000) states that the locus of causality is the only causal dimension that produces achievement-related psychological states (feelings of increased competence), which may conceptually relate to self-efficacy. Bandura (1997) suggested that past performance feedback would subsequently have effects on self-efficacy and, in turn, on future performance, which will vary depending on whether performance feedback is attributed causally to internal or external factors.

Different levels of self-efficacy (high vs. low) may affect different types of causal attributions (internal vs. external) for different conditions of performance feedback (success vs. failure). Individuals weigh up, integrate and evaluate information about their capabilities and then regulate their choices and efforts accordingly (Bandura, Adams, Hardy, \& Howells, 1980). For example, in a lab study of 95 participants, Stajkovic and Sommer (2000) observed that the interaction between initial self-efficacy and performance feedback affected causal attributions, which were in turn a significant predictor of subsequent self-efficacy, which in turn predicted future performance. Individuals high on self-efficacy attributed success to internal factors (and failures to external factors), which enhance performance success and subsequent self-efficacy. But individuals with low scores on self-efficacy make internal attributions for both conditions (success and failure).

This study goes one step further by testing whether past academic success will influence future success, depending on the level of self-efficacy and the causal attribution (internal vs. external) of that past success. Moreover, we will test some past findings on this topic (Stajkovic \& Sommer, 2000) but 
in a field study with students using different measures (objective vs. subjective) and a different time frame (past and future success).

\section{Self-efficacy and Students' Performance}

The positive relationship between self-efficacy and job performance has been shown in previous research (see Stajkovic \& Luthans, 1998). In the academic context, the construct of self-efficacy has received considerable attention from educational psychology researchers, and findings show that selfefficacy is a significant predictor of academic performance (Bandura, Barbaranelli, Caprara, \& Pastorelli, 2001; Pajares \& Schunk, 2005). In fact, efficacy beliefs are thought to be so important to academics that Bandura (1997, p. 216) stated that "perceived self-efficacy is a better predictor of intellectual performance than skills alone".

However, Vancouver and colleagues noted that efficacy beliefs in specific context (training or learning contexts) have negative effects on learning performance (Vancouver \& Kendall, 2006; Vancouver, Thompson, \& Williams, 2001). They claim that when self-efficacy is relatively high, individuals to use fewer resources, high self-efficacy creates relaxation and reduces future performance. So, self-efficacy is likely to play a negative role in resource allocation, which may adversely affect performance.

In opposition, Bandura (1997) and Pajares (1996) argue that students, who believe they can have success academically tend to show greater interest in academic work, set themselves higher goals, make greater efforts, and show more resilience when they encounter difficulties. Students who feel confident in their academic abilities tend to engage in challenging activities that lead to greater competence. In short, students' self-efficacy plays an integral role in their academic motivation, learning, and success (Pajares \& Schunk, 2005). Bandura (1997) hypothesised that students develop their academic self-efficacy by interpreting information from at least from its four sources, particularly from their one's own previous attainment (mastery experience). After students complete an academic task, they must quite naturally interpret and evaluate their results. Judgments of competence are then 
created or revised according to these interpretations. When students believe that their efforts were successful, their confidence in successfully accomplishing similar or related tasks in the future is raised. Conversely, when they believe that their efforts failed to produce the desired effect, their confidence in succeeding in similar endeavours diminishes. However, Flores (2007) found different results: no effect of self-efficacy as a predictor of academic performance (postgraduate expectations, university Grade Point Average - GPA).

Recently, results from a meta-analysis (Brown et al., 2008) using Structural Equation Modelling for secondary school show that self-efficacy leads to academic success, in part because individuals with high self-efficacy beliefs work towards achieving more challenging academic goals. Findings show that past performances in similar contexts are the most influential sources of efficacy beliefs in academic contexts, and that their influences on success are at least mediated by self-efficacy.

A great deal of research has been carried out on students' self-efficacy, and achievement. However, not many studies have related self-efficacy, causal attribution and performance, in the particular case of educational contexts. The aim of this study is to test how self-efficacy influences future success depending on the causal attribution of past academic success (internal vs. external positive performance). Social Cognitive Theory predicts that people with high self-efficacy will probably make an internal causal attribution of their success, which in turn predicts future success. However, it is also possible for people with high levels of self-efficacy to make an external attribution of past success. In these cases, a prediction of bad performance in the future can occur. In other cases, it is possible that past academic success influences self-efficacy, which in turn influences future academic success, depending on the causal attribution of performance. More specifically, we hypothesise that:

Hypothesis 1. Academic self-efficacy and internal/external causal attribution consecutively mediate between past and future academic success. That is, academic self-efficacy and 
internal/external causal attribution plays a mediating role among past and future academic success.

Hypothesis 2. Past academic success has a positively and significant relationship on academic self-efficacy, which in turns is positively related to internal causal attribution, which is positively related to future academic success.

Hypothesis 3. Past academic success has a positively and significant relationship on academic self-efficacy, which in turn is positively related to external causal attribution, which is negatively related to future academic success.

INSERT FIGURE 1 ABOUT HERE

Method

\section{Sample and Procedure}

A cross-sectional field study was carried out on students from a public university in Spain in 2001 and 2003. A stratified sample of 867 students was recruited from 6,000 undergraduate students. The sample was randomly selected using a strategy of sample stratification by segmentation (schools) with a margin of error of 0.015 and $90 \%$ confidence: Faculty of Humanities and Social Sciences, Faculty of Law and Economics, and School of Science and Technology. The final sample consisted of 527 students (67\% were female) from social and behavioural sciences (40\%), chemistry and engineering $(33 \%)$ and law $(27 \%)$. The mean age of the sample was 22 years ( $\mathrm{SD}=2.6$; range from 18 to 43$)$. From the original sample 867 students 340 students did not fill in their identification number and so it was impossible to link their questionnaire data with the university Grade Point Average (GPA; objective data administered by the university).

At the beginning of the academic year, we sent a letter to students' Vice-Chancellor of the University, deans, and department managers. In this letter the goal of the research was explaining and the participation permission was agreed. After the informed consent of teachers whose students participated in the research, the study began. Psychology students, who were properly trained, handed 
out the questionnaires ( 15 minutes to be filled in) to the students before the beginning of a lecture. The questionnaires were given out in envelopes together with a cover letter explaining the purpose of the study and that participation was voluntary. Students returned the completed questionnaires in a sealed envelope to the researchers. As for the ethical issues, research ensured strict compliance with applicable regulations, especially with regards to the utmost voluntarily participation and confidentiality in handling data, ensuring at all times that the guidelines governing this were based on the usual rigor of scientific research.

\section{Measures}

Past and future academic success was assessed by their objective performance (Grade Point Average) as reflected by the GPA (from 0 to 10) from the beginning of their studies until the semester prior to distribution of the questionnaire (past academic success) and the semester after it (future academic success). The participant's permission was obtained for receiving their GPA and the confidentiality was guaranteed.

Academic self-efficacy was measured with five items on the Spanish version of Midgley et al.' scale (2000) from 1 'completely disagree' to 7 'entirely agree'. It reflects specific student beliefs in their future capacities to produce accurate levels of academic success (e.g. 'I will be able to do the more complicated work in class if I try hard enough'; alpha $=.83$ ).

Causal attribution was assessed by ten self-construed items related to internal and external causes of good past success. Internal attribution referred to personal resources that facilitated students' past performance, i.e. personal motivation, personal positive expectations about the job market and about successfully completing their studies, personal traits and showing autonomy in their studies (five items; 'I had a good academic performance because of my personal motivation)'. External attribution referred to both organisational and social resources that facilitated students' past success, such as administrative services, good teaching structure, campus information services, good social relationships with teaching staff and colleagues alike (five items; 'I had a good academic performance 
because of the good teaching structure at the University'). Students were asked to indicate whether or not (yes or no) each (internal and external) indicator accounted for their past success. Alpha values were not included since were a dummy variable (yes/no).

\section{Data Analyses}

First we calculated descriptive analyses and inter-correlations using the SPSS 19.0. Second, we computed the Harman's single factor test (Podsakoff, MacKenzie, Lee, \& Podsakoff, 2003; p. 889) on attribution and self-efficacy (past and future success are objective data) by AMOS 19.0 to test for bias due to common method variance. Third, we implemented Structural Equation Modeling (SEM) by AMOS 19.0 to test the hypothesized model following the recommendations for mediating analyses for latent constructs and multiple mediators (James, Mulaik, \& Brett, 2006). The different steps of Baron and Kenny (1986) with latent factors and the Sobel's (1982) test as significance for the indirect effects were computed (cf. Wood et al., 2008). Following James et al. (2006, p. 243), who states that the objective of the SEM is “...to contrast alternative models and identify those that appear to offer useful explanations versus those that do not", three models were tested in other to verify the hypothesis: M1, the Proposed Fully Mediated Model, in which past academic success is positively related to future academic success through academic self-efficacy and (internal/external) causal attribution (see Figure 1); M2, the Partially Mediated Model in which a direct relationship was also included from past to future academic success (see Figure 2); M3, the Partially Mediated Model in which a direct relationships were also included from academic self-efficacy to future academic success and from past academic success to (internal/external) causal attribution (see Figure 3). Finally, as recommended by Kline (1998), we test an alternative model to determine that the order of the mediating variables in a given model is not arbitrary. Consequently, $\mathrm{M} 4^{1}$, in which academic self-efficacy is mediating the relationship between internal/external causal attribution and future academic success, is tested (see Figure 4). 


\section{INSERT FIGURE 3 ABOUT HERE \\ INSERT FIGURE 4 ABOUT HERE}

The $\chi^{2}$ Goodness-of-Fit Statistic $(p>.05)$, relative chi-square ( $\chi^{2} / d f$; up to 5.0), Root Mean Square Error of Approximation (RMSEA; <.05), Akaike Information Criterion (AIC; lower), as well as Comparative Fit Index (CFI), Incremental Fit Index (IFI), Non-Normed Fit Index or Tucker-Lewis Index (TLI) (> .90) were used to evaluate the goodness-of-fit of the models (Hornung \& Glaser, 2010; Hoyle, 1995; James, Mulaik, \& Brett, 1982).

\section{Results}

\section{Descriptive Analyses}

Table 1 displays the descriptive analyses and inter-correlations. As expected, the pattern of correlations shows that all scales interrelate positively and significantly. Unexpectedly, we find a nonsignificant correlation between external attribution and future academic success. The Harman's single factor test reveals that a common method variance is not a serious deficiency in this dataset, $\chi^{2}(1)=$ 10.14, $\mathrm{RMSEA}=.13, \mathrm{CFI}=.86, \mathrm{IFI}=.87$ and $\mathrm{TLI}=.60$.

\section{INSERT TABLE 1 ABOUT HERE}

\section{Model Fit: Structural Equation Modelling}

Table 2 displays the results of the SEM analyses. In accordance with Baron and Kenny (1986) we fit our proposed fully mediated model (M1) to the data. The model consists of one exogenous (past academic success) and four endogenous variables (academic self-efficacy, internal and external attribution and future academic success). Academic self-efficacy as well as internal and external causal attribution comprises two indicators each one: the first indicator is composed by two items (items 1 and 2), and the second indicator is composed by three items (items 3, 4 and 5). Results indicate that M1 in which past academic success are positively related to future academic success through self-efficacy and attribution does not fit the data well ${ }^{2}$. Chi-square differences between M1 and M2, a partial mediation model in which we included a direct relationship from past to future 
academic success, shows a significant difference between both models, Delta $\chi^{2}(3)=442.20, p<.001$, in favour of M2. Thirdly, we tested M3: a partial mediation model in which we also included direct relationships from past academic success to causal attribution as well as from self-efficacy to future academic success. Chi-square differences show a significant difference between M1 and M3, Delta $\chi^{2}(6)=444.10, p<.001$, but a non-significant differences between M2 and M3, Delta $\chi^{2}(3)=1.9, n s$. These results give evidence for the M2 since: (1) it is more parsimonious than M3, and (2) for M3 the direct paths between past academic success and causal attribution, as well between academic selfefficacy and future academic success, are non-significant.

Concerning the mediation process three out four conditions (Baron \& Kenny, 1986; cf. Wood et al., 2008) are met and tested in M2 (our best model): (1) past academic success is positively and significantly related to the mediating variables: causal attribution, $\beta=.26, p<.001$, and to academic self-efficacy, $\beta=.49, p<.001 ;(2)$ past academic success is positively and significantly related to future academic success, $\beta=.96, p<.001$; (3) causal attribution, $\beta=.26, p<.001$, and academic selfefficacy, $\beta=.39, p<.001$, are positively and significantly related to future academic success. However, the relationship between past academic success and future academic success continues becoming significantly, $\beta=.72, p<.001$, when it is controlled by the effect of the mediating variables. And more, the relationship between academic self-efficacy and future academic success is nonsignificant, $\beta=.06, p=.520$, when it is controlled by the effect of the mediating variables. The fact that the relationship between past academic success and future academic success became significant indicated that academic self-efficacy and causal attribution do not fully mediate between past and future academic success. Results of the Sobel's test (1982; see Wood et al., 2008) show that mediators (academic self-efficacy and causal attributions) significantly carry the influence of the past academic success to future academic success. That is, the indirect effect of the past academic success on future academic success through academic self-efficacy (Sobel's test $=2.66, p<.001$ ) and causal attribution (Sobel's test $=2.55, p<.01)$ is statistically significant. 
As recommended by Kline (1998) we test an alternative model to determine that the order of the mediating variables in a given model is not arbitrary. Consequently, $\mathrm{M}^{3}$, in which academic selfefficacy is mediating the relationship between causal attribution and future academic success, is tested. As expected, results give again evidence for the M2 since: (1) M4 shows higher chi-square value than $\mathrm{M}^{4}$; (2) M4 shows worst fit indices compared to M2; (3) for M4 the direct paths between past academic success and external causal attribution, as well as between external causal attribution and academic self-efficacy are non-significant.

In conclusion, previous results using SEM and mediation analyses provide convincing evidence for M2. Figure 5 shows a graphic representation of this best model. All the manifest variables loaded significantly on the intended latent factors, ranging from .37 to .74 . According to the paths, and as expected, past academic success have a positive significant relationship with academic self-efficacy, $\beta=.31, p<.001\left(\mathrm{R}^{2}=10 \%\right)$, which in turn also has a significant and positive relationship with internal causal attribution, $\beta=.64, p<.001\left(\mathrm{R}^{2}=41 \%\right)$ which in turn, have a significant and positive relationship with future academic success, $\beta=.17, p<.001\left(\mathrm{R}^{2}=10 \%\right)$. Furthermore, academic self-efficacy also has a significant and positive relationship with external causal attribution, $\beta=.38, p<.001\left(\mathrm{R}^{2}=14 \%\right)$ which in turn, have a significant but negative relationship with future academic success, $\beta=-.09, p<.05\left(\mathrm{R}^{2}=5 \%\right)$. Finally, past academic success also have significant and positive relationship with future academic success by a direct effect, $\beta=.73$, $p<.001\left(\mathrm{R}^{2}=43 \%\right)$.

INSERT TABLE 2 ABOUT HERE

INSERT FIGURE 5 ABOUT HERE

\section{Discussion}

Taking the Albert Bandura's SCT as its theoretical framework, in the current study, we researched into the relationship among academic success, academic self-efficacy and causal attribution (internal vs. external) in university students. The SCT assumes that self-efficacy perceptions exert an 
influence on motivation in specific behaviors such as high performance (Bandura, 1995). The main research question addressed was whether the influence of academic self-efficacy on future academic success, depends on the causal attribution of past good performance (internal vs. external attribution). The objective of the present study was to test both the role of causal attribution (internal vs. external) and how academic self-efficacy predicts future academic success.

Past and future academic success were conceptualised by objective performance reflected by the GPA from the beginning of the students' studies until one semester before handing out the questionnaire, and one semester after. Based on previous studies which support the measurement of efficacy beliefs by using specific scales in specific domains (Salanova et al., 2002, 2003), we used the specific academic self-efficacy, i.e. beliefs related to the students' beliefs about their future capacities to produce accurate levels of academic success. Finally, we measured causal attribution by two different indicators that are internal or external causes of good past performance.

Results of the SEM analyses in a sample of 527 university students supported all the hypotheses. More specifically, results revealed that academic self-efficacy and causal attribution consecutively mediate between past and future academic success. Also, results note the relevant and direct path among past and future academic success. According to SCT, when students believe that their efforts were successful, their confidence in successfully accomplishing similar or related tasks in the future is raised. These results partially confirm our Hypothesis 1 since academic self-efficacy and causal attribution plays a mediation role among past and future academic success but this relationship is not absolutely fully mediating.

Furthermore, and attending to the theoretical model, it was the one that best fits the empirical data: past academic success is positively related not only to future academic performance but also students' academic self-efficacy. At the same time, academic self-efficacy influences future academic success, not in a direct way but fully mediated by the internal attribution of past academic success, thus confirming Hypothesis 2. Attributions of success to internal causes are accompanied by 
heightened beliefs of personal efficacy, which, in turn, predict subsequent performance attainments (Bandura, 1997). Results also suggest that past academic success increases levels of academic selfefficacy, which in turn increases external attribution. As expected, this external attribution would decrease future academic success. Results revealed that those students who make an external attribution of past academic success displayed lower academic success in the future, thereby supporting Hypothesis 3.

Briefly, this study in educational settings is congruent with the SCT of Bandura and shows that self-efficacy, causal attributions and academic performance, are related. In this relation, the selfefficacy and causal attribution have a mediating role between past and future performance.

\section{Theoretical Implications}

Our results enable us to draw three relevant conclusions. Firstly, our findings show the relevance of mastery experiences/past performance in the prediction of future academic performance. Particularly, past academic success is a good predictor of future academic success; hence, 'success leads to success' $\left(\mathrm{R}^{2}=43 \%\right)$. However, the rest of the variance is accounted for by the psychosocial constructs: causal attributions. Although the influence of causal attributions on future academic success were significant in both cases, the impact of internal attribution on future academic success was higher $\left(\mathrm{R}^{2}=10 \%\right)$ than the impact of external attribution $\left(\mathrm{R}^{2}=5 \%\right)$.

Secondly, our results offer empirical evidence that prior academic performance/mastery experiences are linked to academic self-efficacy beliefs. They provide evidence (since the current study is both retrospective and prospective) of the influences between academic performance and academic self-efficacy. According to the Social Cognitive Theory, the effects of past performance provide feedback on subsequent self-efficacy and, in turn, on future performance, which will vary depending on whether performance feedback is causally attributed to internal or external factors.

Thirdly, the pivotal role of the causal attribution process between self-efficacy and future academic success were shown. Academic self-efficacy is not the only the relevant psychological 
variable influencing future academic success. Only when people attribute past academic success to internal causes will future success improve. These results also provide evidence that the relationship between self-efficacy and future performance is not direct but instead fully mediated by causal attribution. In accordance with previous research (Flores, 2007), self-efficacy is not a direct predictor of future academic success, and in fact this relationship between self-efficacy and success is mediated by causal attribution. Hence, a positive relationship only exists with future success when carrying out an internal attribution of the last success and the corresponding level of self-efficacy. Yet this relationship is negative when carrying out an external attribution.

To summarise, students make causal attributions about their success, which could potentially be internal (motivation, personality, effort) or external (good teachers, good relationship among colleagues). The process is as follows: when people with a high level of self-efficacy make an internal attribution about their good past success, this then predicts good future performance. However, when an external attribution takes place among people with high self-efficacy, it will influence bad performance in the future. These results provide evidence for a potential performance cycle where self-efficacy, causal attributions and performance are reciprocally related over time. Results also show that past performance/mastery experiences are an important source of future performance, since their influence is not only direct but also indirect, that is, through the self-efficacy and the causal attribution of good past performance. Only when people make an internal attribution of good past performance will it positively influence future good performance (Flores, 2007; Stajkovic \& Sommer, 2000). This therefore allows us to show the key role of causal attribution in the relation between past and future academic success and academic self-efficacy.

\section{Practical Implications}

At a practical level results indicate that one way to intervene in and optimise academic success of university students is to generate the belief that they are able to do their work successfully and, above all, that these results are the consequence of this internal potential (motivation, personality and effort) 
and do not derive from external factors such as good teachers or good relationships with colleagues, for example. The findings also stress the role of educational institutions and teachers in promoting academic self-efficacy and an internal attribution of past academic success. Training should include a variety of components that are consistent with theoretical cues for building efficacy (Bandura, 1997): the use of role-playing to provide experiences of success, performance models by vicarious experiences, coaching and social persuasion from teachers. Further research should aim to explain the unknown variance and to identify the factors that influence students' academic success to improve the students' GPA, but also to ensure that students will finish their degree studies and future post-graduate expectations.

\section{Study Limitations and Future Research}

The chief limitation of the study is that a longitudinal design has not been used. Consequently, results are restricted to influence effects (Cole \& Maxwell, 2003). However, a number of strong points may also be highlighted: (1) its retrospective and prospective design, (2) the proposed model includes not only subjective (academic self-efficacy and causal attribution) but also objective measures (past and future academic performance), and (3) it is confined to the context of university students.

Future research could be extended to test the model using: (1) longitudinal cross-lagged panel designs with two or three waves to test the long-term effects of these reciprocal relationships over time; (2) students from different universities and countries in order to test its robustness, and (3) the relationship among past academic failure and academic self-efficacy and the role of the causal attribution. 


\section{References}

Bandura, A. (1997). Self-efficacy: The exercise of control. New York: Freeman.

Bandura, A. (2001). Social cognitive theory: An agentic perspective. Annual Review of Psychology, 52, $1-26$

Bandura, A. (2008). Toward an agentic theory of the self. In H. Marsh, R. G. Craven, \& D. M. McInerney (Eds.), Advances in Self Research, Vol. 3: Self-processes, learning, and enabling human potential (pp. 15-49). Charlotte, NC: Information Age Publishing.

Bandura, A., \& Locke, E. A. (2003). Negative self-efficacy and goal effects revisited. Journal of Applied Psychology, 88, 87-99.

Bandura, A., Adams, N. E., Hardy, A. B., \& Howells, G.N. (1980). Test of the generality of selfefficacy theory. Cognitive Therapy and Research, 4, 39-66.

Bandura, A., Barbaranelli, C., Caprara, G. V., \& Pastorelli C. (2001). Self-efficacy beliefs as shapers of children's aspirations and career trajectories. Child Development, 72, 187-206.

Baron, R. M., \& Kenny, D. A. (1986). The moderator-mediator variable distinction in social psychological research: Conceptual, strategic, and statistical considerations. Journal of Personality and Social Psychology, 51, 1173-1182.

Beas, M.I \& Salanova, M. (2006). Self-efficacy Beliefs, Computer Training and Psychological WellBeing among Information and Communication Technology Workers. Computers in Human Behavior, 22, 1043-1058.

Bresó, E., Salanova, M. \& Schaufeli, W.B. (2007). In search of the ‘third dimension’ of burnout. Applied Psychology: an international review, 56, 460-478.

Bresó, E., Schaufeli, W.B. \& Salanova, M. (2011). Can a Self-efficacy-Based Intervention Decrease Burnout, Increase Engagement, and Enhance Performance? A Quasi-experimental Study. Higher Education, 61, 339-355. 
Brown, S., Tramayne, S., Hoxha, D., Telander, K., Fan, X., \& Lent, R.W. (2008). Social cognitive predictors of college students' academic performance and persistence: A meta-analytic path analysis. Journal of Vocational Behavior, 72, 298-308.

Cole, D. A., \& Maxwell, S. E. (2003). Testing mediational models with longitudinal data: questions and tips in the use of structural equation modeling. Journal of Abnormal Psychology, 112, 558577.

Fiske, S. \& Taylor, S. (1991) Social Cognition. New York: Mcgraw-Hill Inc.

Flores, A. (2007). Attribution style, self-efficacy, and stress as predictors of academic success and academic satisfaction in college students. Dissertation Abstracts International Section A: Humanities and Social Sciences, 68, 874- 874.

Hornung, S., \& Glaser, J. (2010). Employee responses to relational fulfilment and work-life benefits. International Journal of Manpower, 31, 73-92.

Hoyle, R. H. (1995). The Structural Equation Modeling Approach: Basic Concepts and Fundamental Issues. In R. H. Hoyle (ed.), Structural Equation Modeling, Concepts, Issues and Applications (pp. 1-15). Thousand Oaks, Ca: Sage.

James, L. R., Mulaik, S. A., \& Brett, J. M. (2006). A tale of two methods. Organizational Research Methods, 9, 233-244.

James, L. R., Mulaik, S. S., \& Brett, J. M. (1982). Causal Analysis. Beverly Hills, CA: Sage.

Katzel, R. A., \& Thompson, D. E. (1990). Work motivation: theory and practice. American Psychologist, 45, 144-156.

Klassen, R. (2004). A cross-cultural investigation of the efficacy beliefs of South Asian immigrant and Anglo non-immigrant early adolescents. Journal of Educational Psychology, 96, 731-742.

Kline, R. B. (1998). Principles and Practice of Structural Equation Modeling. New York, NY: Guilford Press. 
Lent, R. W., Taveira, M. C., Sheu, H-B., \& Singley, D. (2009). Social cognitive predictors of academic adjustment and life satisfaction in Portuguese college students: A longitudinal analysis. Journal of Vocational Behavior, 74, 190-198.

Lyden, J. A., Chaney, L. H., Danehower, V. C., \& Houston, D. A. (2002). Anchoring, Attributions, and Self-Efficacy: An Examination of Interactions. Contemporary Educational Psychology, 27, 99-117.

Midgley, C., Maehr, M. L., Hruda, L. Z., Anderman, E., Anderman, L., Freeman, K. E., Gheen, M., Kaplan, A., Kumar, R., Middleton, M. J., Nelso, J., Roeser, R., \& Urdan, T. (2000). Manual for Patterns of Adaptive Learning Scales. University of Michigan Press.

Pajares, F. (1996). Self-efficacy beliefs in academic settings. Review of Educational Research, 66, 543-578.

Pajares, F., \& Schunk, D. H. (2005). Self-efficacy and self-concept beliefs: Jointly contributing to the quality of human life. In H. Marsh, R. Craven, \& D. McInerney (Eds.), International advances in self research (Vol. 2, pp. 95-121). Greenwich, CT: Information Age Publishing.

Podsakoff, P. M., MacKenzie, S. M., Lee, J., \& Podsakoff, N. P. (2003). Common method variance in behavioral research: A critical review of the literature and recommended remedies. Journal of Applied Psychology, 88, 879-903.

Salanova, M., Lorente, L., Chambel, M.J. \& Martínez, I.M. (2011). Linking transformational leadership to nurses' extra-role performance: the mediating role of self-efficacy and work engagement. Journal of Advanced Nursing, 67, 2256-2266.

Salanova, M., Llorens, S., Cifre, E., Martínez, I., \& Schaufeli, W. B. (2003). Perceived collective efficacy, subjective well-being and task performance among electronic work groups: An experimental study. Small Group Research, 34, 43-73. 
Sobel, M. E. (1982). Asymptotic confidence intervals for indirect effects in structural equation models. In S. Leinhardt (Ed.), Sociological methodology (pp. 290-312). Washington, DC: American Sociological Association.

Stajkovic, A. D., \& Luthans, F. (1998). Self-efficacy and work-related performance: a meta-analysis. Psychological Bulletin, 124, 240-261.

Stajkovic, A. D., \& Sommer, S. M. (2000). Self-efficacy and causal attributions: Direct and reciprocal links. Journal of Applied Social Psychology, 30, 707-737.

Vancouver, J. B., \& Kendall, L. N. (2006). When self-efficacy negatively relates to motivation and performance in a learning context. Journal of Applied Psychology, 91, 1146-1153.

Vancouver, J. B., Thomson C. M., \& Williams, A. A. (2001). The changing signs in the relationships among self-efficacy, personal goals and performance. Journal of Applied Psychology, 86, 605620.

Weiner, B. (1985). An attributional theory of achievement motivation and emotion. Psychological Review, 92, 548-573.

Weiner, B. (1986). An attributional theory of motivation and emotion. New York, NY: SpringerVerlag.

Wood R. E., Goodman J. S., Beckmann N., \& Cook, A. (2008). Mediation Testing in Management Research: A Review and Proposals. Organizational Research Methods, 11, 2, 270-295. 
Notes:

1. The direct path from past to future academic success is also included.

2. The error variance of academic self-efficacy (indicator 1) and external causal attribution (indicator 2) were constrained to avoid unidentified problems by using the formula, $(1-\alpha) * \sigma 2$ (Stephenson \& Holbert, 2003).

3. The direct path from past to future academic success is also included.

4. Since both models have the same degrees of freedom, testing of chi-square differences is not applicable. 
Table 1

Means $(M)$, Standard Deviations ( $S D)$, and correlations of the variables in the study $(N=527)$

\begin{tabular}{lcccccc}
\hline \multicolumn{1}{c}{ Variables } & $M$ & SD & 1 & 2 & 3 & 4 \\
\hline 1.Past academic success & 6.58 & .74 & - & & & \\
2. Academic self-efficacy & 4.08 & 1.07 & $.15^{* *}$ & - & & \\
3. Internal causal attribution & .24 & .25 & $.15^{* *}$ & $.24 * * *$ & - & \\
4. External causal attribution & .17 & .22 & $.08^{*}$ & $.19^{* * *}$ & $.23^{* * *}$ & - \\
5. Future academic success & 6.60 & .66 & $.75^{* * *}$ & $.14^{* *}$ & $.18^{* * *}$ & .02 \\
& & & & & & \\
\hline Note. $* p<.05, * * p<.01, * * * p<.001$. & & & & &
\end{tabular}


Table 2

Fit indices of the competitive models $(N=527)$

\begin{tabular}{|c|c|c|c|c|c|c|c|c|c|c|c|c|c|c|c|}
\hline Model & $\chi^{2}$ & $d f$ & $p$ & $\chi^{2} / d f$ & RMSEA & CFI & NFI & IFI & AIC & $\chi^{2}$ diff & $\triangle \mathrm{RMSEA}$ & $\Delta \mathrm{CFI}$ & $\Delta \mathrm{NFI}$ & $\Delta \mathrm{IFI}$ & $\Delta \mathrm{AIC}$ \\
\hline Model 1 (M1) & 470.97 & 19 & .000 & 24.78 & .210 & .39 & .39 & .41 & 504.97 & & & & & & \\
\hline Model 2 (M2) & 28.77 & 16 & .026 & 1.79 & .039 & .98 & .96 & .98 & 68.77 & & & & & & \\
\hline Diff. M2 \& M1 & & & & & & & & & & $444.2 * * *$ & .171 & .59 & .57 & .57 & 436.2 \\
\hline Model 3 (M3) & 26.87 & 13 & .013 & 2.06 & .045 & .98 & .96 & .98 & 72.87 & & & & & & \\
\hline Diff. M3 \& M2 & & & & & & & & & & 1.9 & .006 & .000 & .000 & .000 & 4.1 \\
\hline Model 4 (M4) & 63.18 & 16 & .000 & 3.94 & .070 & .94 & .92 & .94 & 103.18 & & & & & & \\
\hline Diff. M4 \& M2 & & & & & & & & & & - & .031 & .040 & .040 & .040 & 34.41 \\
\hline Diff. M4 \& M3 & & & & & & & & & & $36.31 * * *$ & .025 & .040 & .040 & .040 & 30.31 \\
\hline
\end{tabular}

Notes: $\chi^{2}=$ Chi-square; $d f=$ degrees of freedom; $p=$ probability; $\chi^{2} / d f=$ relative chi-square; RMSEA= Root Mean Square Error of Approximation;

$\mathrm{CFI}=$ Comparative Fit Index $; \mathrm{NFI}=$ Normed Fit Index; IFI = Incremental Fit Index; AIC = Akaike Index Criterion; $* * * p<.001$. 
Figure 1. Model 1: The proposed fully mediated model.

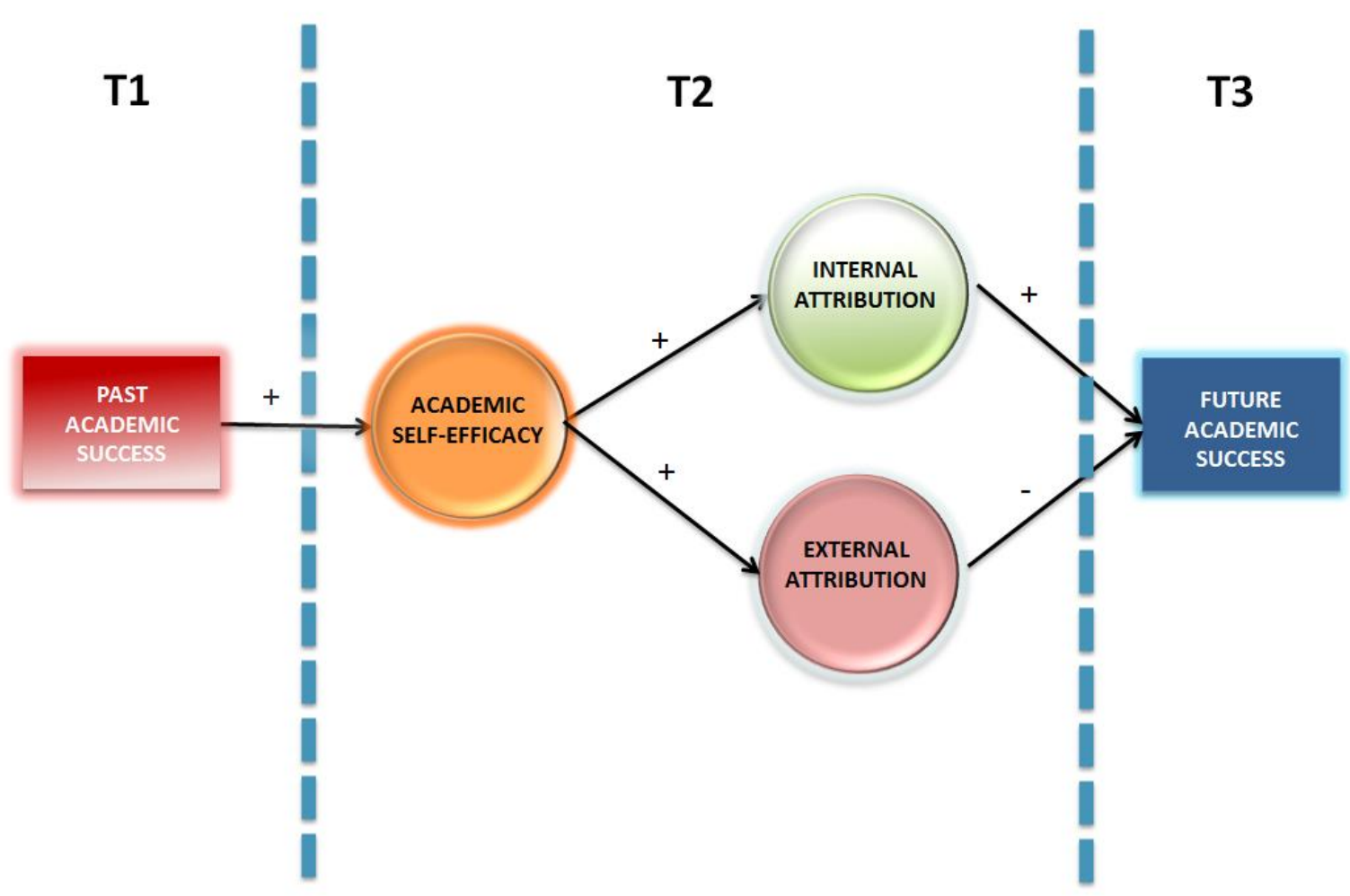


Figure 2. Model 2: The partially mediated model.

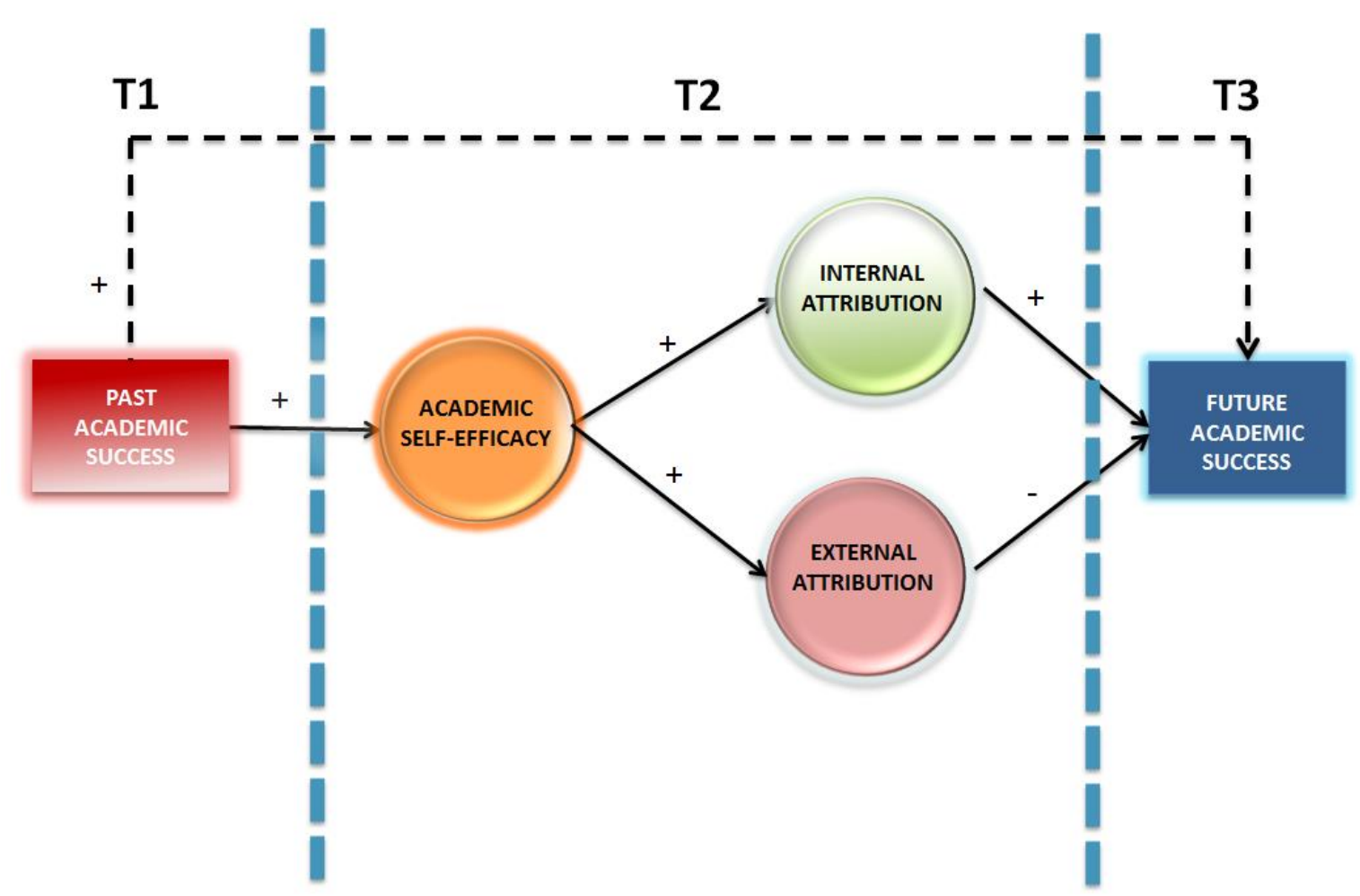


Figure 3. Model 3: The partially mediated model (bis).

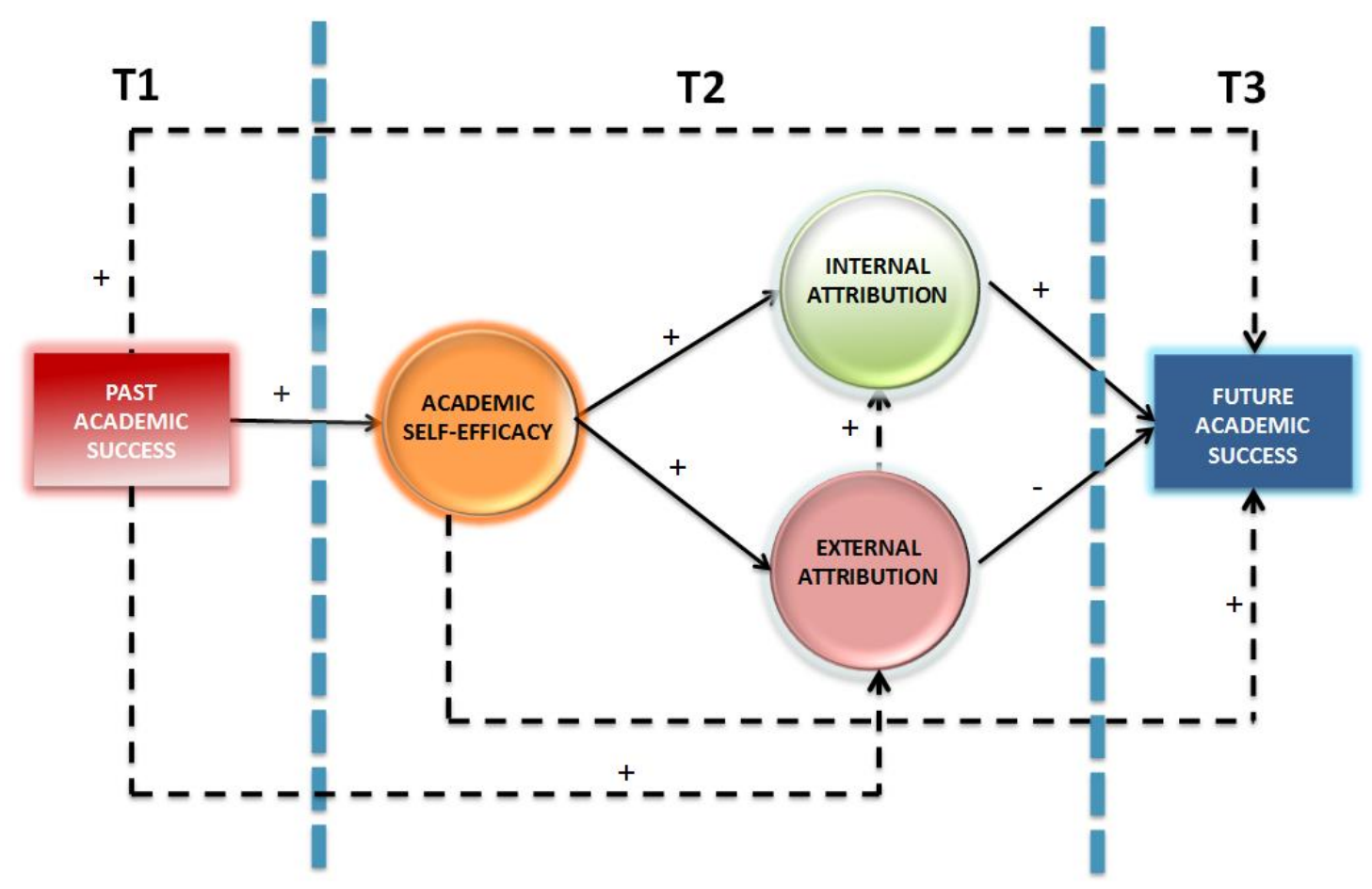


Figure 4. Model 4: The alternative model.

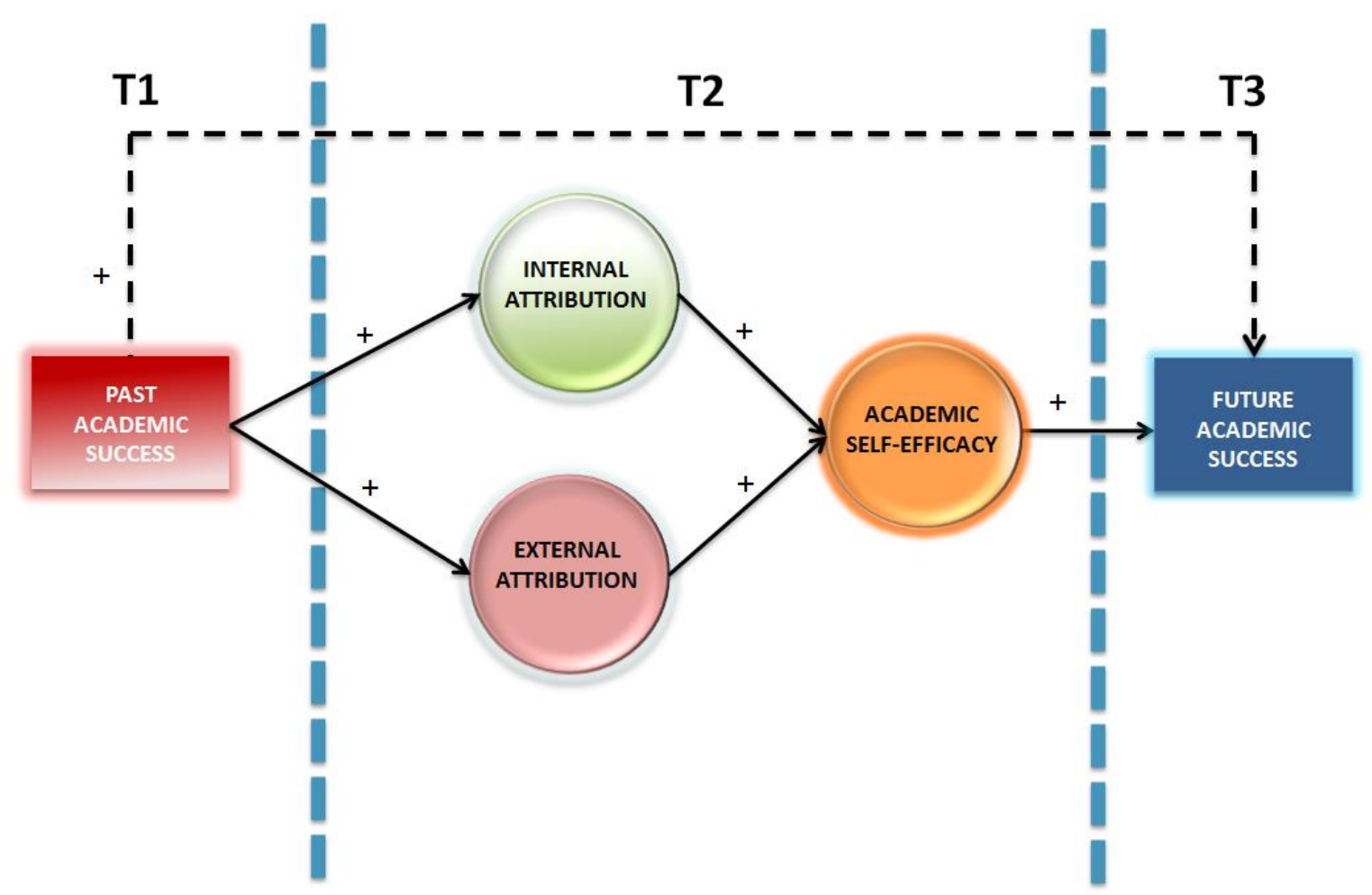


Figure 5. Structural model of academic success, academic self-efficacy and causal attribution $(\mathrm{N}=527)$. Note. Significant standardised path coefficients are significant at $* * * p<.001, * p<.05$.

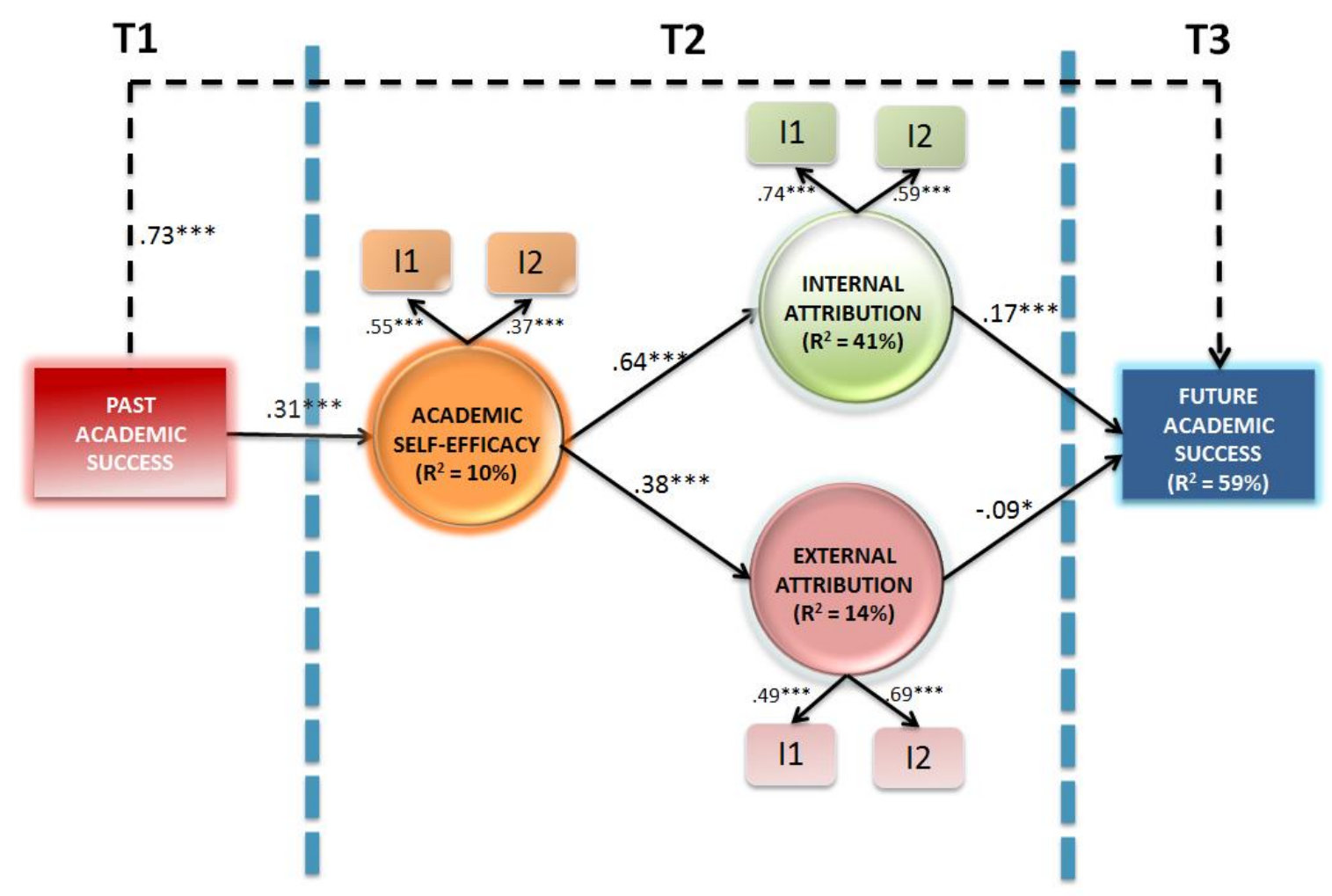

